\title{
Doctors as performance artists
}

\author{
Michael O’Donnell MB FRCGP
}

J R Soc Med 2005;98:323-324

ABSTRACTED FROM THE 32ND ALBERT WANDER LECTURE, SECTION OF GENERAL PRACTICE WITH PRIMARY HEALTH CARE, 21 APRIL 2005

My father was a GP in a Yorkshire village and used to take me with him in his car and into patients' houses when he indulged in that strange habit doctors once had of visiting the sick. That's when I discovered that, in the presence of patients, he became a performer. Later when I worked briefly as his assistant I saw how he suited his performance to the occasion: most often he would play the kindly, wise, and sympathetic counsellor, sometimes the cheery motivator driving away dull care, sometimes the cool assessor defining decisions his patients needed to make.

I also discovered that he had acquired much of his understanding of medicine from his patients, in the way that performers learn from their audience. True, he picked up useful knowledge from books and journals but he screened everything he read through the filter of his own experience.

I've since met lots of GPs who performed in much the same way and concluded that the empathy they have with their patients is one of the elusive qualities possessed by doctors whom patients feel better for seeing, whatever the treatment they prescribe-doctors whom some call 'healers'.

I've also concluded that the source of this empathy - the ability to see the world as it appears in the eyes of their audience - is the same for doctors as it is for the actors and writers with whom I've worked in the second phase of my career. For most human actions, I suggest, you can define two reasons: a good reason and a real reason. Performers, be they actors, writers, or doctors, seek out life's real reasons and, if they're lucky, discover the person who lurks behind the social façade.

If a performance is to succeed it must appear to be truthful, even if the truth exists only in the eyes and ears of the audience. The audience perceives a real person, real emotion; the skill of the performer blinds them to the artifice that has to be employed. The late Sir Alec Guinness described the process to me over the relics of a memorable lunch. All of the body and nine-tenths of the mind, he said, must be devoted to producing a convincing truthful performance. Yet in a tiny corner of the brain sits the pilot with his hands on the controls, coolly monitoring

Handon Cottage, Markwick Lane, Loxhill, Godalming GU8 4BD, UK

E-mail: michael@odonnell199.freeserve.co.uk

(C) Michael O'Donnell 2005 timing and audience reaction, remembering lines and rehearsed moves, yet knowing that a false move on his part will impair the seemingly impromptu physical performance.

Allowing the artifice to show can have catastrophic effects in playhouse or consulting room. I quickly learned as a GP never to seek to reassure, advise, or win trust by assuming a false persona.

Drama students are encouraged early in their training to analyse their motives and their personalities because, as one of their teachers put it, 'an actor working at full pitch operates with the substance of his or her own life. . . . The degree to which a performance is convincing often reflects the extent to which the actor is able to draw truthfully on his or her own essence'. ${ }^{1}$ This is the crucial distinction between performing, which is a creative activity, and the playing of roles which is not.

The commonest medical role-players are doctors who assume a 'bedside manner', by which they mean charm or sympathy switched on as a deliberate technique - the smile that is swiftly wiped on and even more swiftly wiped off, the show of interest that lives only in the lips and cheeks while the eyes remain dead. I doubt that their antics reassure patients. As the good Dr Johnson said: 'Almost all absurdity of conduct arises from the imitation of those we cannot resemble'. ${ }^{2}$

Even the most versatile of actors know there are limits to the range of parts they can play, imposed by their personality, their physical shape and what Athene Seyler, actress and teacher, called their 'spiritual comprehension' of the part. She described a versatile actor whose one failure was in expressing coarseness. 'He may assign the externals of a coarse-minded man in his make-up, way of walking, clothes and manner, but his approach to the character is imposed from outside and he never succeeds in convincing the audience of its truth' ${ }^{3}$

Having worked with non-medical performers for over forty years, I find it depressing that so much medical teaching of communication never gets beyond the Janet and John stage of 'communication skills'. John Skelton, professor of clinical communication in the Department of General Practice at the University of Birmingham, wonders why we waste precious time researching 'crashingly obvious' surface skills that have more to do with role playing than with performance. ${ }^{4}$ Phil Hammond has 
described how, as a student, he found it patronizing in the extreme to be told he should greet a patient and establish eye contact. $^{5}$ And Skelton, whom God preserve, has described how, after his first ten years working in medical communication, the banality of much of the research still stopped him in his tracks. ${ }^{6}$

That banality is exemplified in the oft quoted list of Key Communication Skills. It's true, of course, that eye contact is important - as is regularly checking that the patient understands what's being said, asking open questions, not interrupting, and so on - but most doctors keen to improve their performance regard this as pretty obvious.

The diminution of the craft of communicating to the mechanics of role playing encourages us to ignore the limitations imposed by the individual quirks of doctors and their patients - the attributes that Athene Seyler explained impose limits upon actors. It's pretty obvious, for instance, that establishing eye contact with a patient is a Good Thing. Yet, as every actor and observant doctor knows, the quality of eye contact - and how long it is held - can vary with the cultural and social background, the age and gender of those engaged in conversation.

Skelton points out that, to accommodate this variance yet maintain the illusion of a mechanical skill, the academic assessment of communication skills is peppered with equivocating adjectives such as 'appropriate' and 'reasonable'. Appropriate crops up seven times in the schedule for the MRCGP video exam ${ }^{4}$ and a recent paper referred to 'reasonable eye contact' (less easy to judge I suspect than unreasonable eye contact).

Performers are not plagued with these equivocations. For them eye contact - and its nature - is not a measured act imposed by protocol but springs from a deeper level of sensibility. The notion of communication as a mechanical skill implies that a doctor's personality makes a minor contribution to the ability to understand and be understood; the notion of performance acknowledges that a doctor's personality is sometimes the most powerful generator of empathy and understanding. Time devoted to demonstrating 'reasonable eye contact' in front of a video camera might be better spent on a quest for self knowledge.

Reducing a creative craft to a compendium of technical tricks is a neat example of what William Silverman described as 'reductionist snobbery'. Silverman, one of the founders of American neonatal medicine, was a fine provocative essayist, and one of the many conventional beliefs he challenged was the assumption that the only 'scientific' approach to researching complexity is the reductionist one-an approach which would have led Newton to seek the source of gravity by cutting open the fallen apple and cataloguing the structures that lay inside. ${ }^{7}$

Skelton suggests that the attitudes to medicine and professional life that underpin communication skills may be more important than the techniques. So, should teachers concentrate on the techniques in the hope that the attitudes will follow or should they concentrate on the attitudes in the belief that these will generate the skills? Drama teachers concentrate on the attitudes and encourage students to learn more about themselves; teachers of creative writing encourage students to explore the origin of the voice that speaks to the reader when they write.

There are good practical reasons why doctors should follow their example. Only $40 \%$ of new disorders seen by GPs evolve into recognized diseases. ${ }^{8}$ Even when they do, GPs have to treat illness rather than disease and need to understand the feelings of regret, guilt, fear, betrayal, loneliness, and other perplexing emotions that turn the same disease into different illnesses in different people.

Clearly medicine has to be evidence-based yet, even with the few diseases where compelling data exist, clinicians have to weigh the generality of the evidence against the particular needs of the individual. Just as the knowledge doctors acquire from observing and testing their patients can enhance their knowledge of disease, so the understanding they may absorb from literature, or indeed any of the arts, can enhance their perception of the nature of an individual illness.

The more a medical performance is based on understanding, the more likely it is to be therapeutic. We vaguely recognize this - we once used to talk about the healing art - but now we have so many high-tech toys to play with we seem ashamed to acknowledge its existence, especially since accountants conquered the world and decreed that success be measured in 'outcomes' they can manipulate in spreadsheets.

These fiscal measures of success appeal to politicians and health managers but have less meaning for GPs. For them the ultimate 'outcome' is a patient's death and 'success' lies in helping people survive the short time they spend on this planet in some sort of harmony with the world around them.

\section{REFERENCES}

1 Clements P (Principal, Mountview Academy of Theatre Arts). Display of artistic integrity. Guardian 23 June, 2001

2 Johnson S. Quoted in Alec Guinness: Commonplace Book. London: Hamish Hamilton, 2000:29

3 Seyler A, Haggard S. The Craft of Comedy. London: Muller, 1943:18

4 Skelton JR. Everything you were afraid to ask about communication skills. Br J Gen Pract 2005;55:40-6

5 Hammond P. Trust me, I'm a communicator. Br J Gen Pract 2005;55:34

6 Skelton JR [http://bmj.com/cgi/eletters/325/7366/697\#26165]

7 Silverman WA. The divisive effect of reductionist snobbery. Pediatr Res 1983; $17: 518$

8 Rosser WW. Application of evidence from randomised controlled trials to general practice. Lancet 1999;352:661-4 